\title{
TECNOLOGIAS DIGITAIS: CRIAÇÃO E UTILIZAÇÃO DE MÍDIAS SOCIAIS COMO FERRAMENTA EDUCACIONAL PARA A TEMÁTICA AMBIENTAL E O ENSINO DE CIÊNCIAS
}

\author{
Vitória Catarina Cardoso Martins ${ }^{1}$ \\ Raquel Macedo Cardoso ${ }^{2}$ \\ Aldo Nascimento Pontes ${ }^{3}$ \\ Altem Nascimento Pontes ${ }^{4}$
}

Resumo: Este trabalho teve como objetivo apresentar o blog educativo (edublog) como ferramenta educacional para o ensino de Ciências e Educação Ambiental. A coleta de dados foi realizada por meio de questionários, que permitiram a identificação das temáticas ambientais que mais causavam interesse dos estudantes da educação básica e do ensino superior de diferentes instituições de ensino de Belém-PA. Com base nas respostas obtidas, foram selecionados 22 temas e, na sequência, desenvolveu-se o edublog e uma página no facebook. Após a aplicação com uma turma de graduação, os resultados indicaram que para ser empregado em sala de aula o professor deve conhecer os materiais a serem utilizados para que proporcionem uma aprendizagem colaborativa.

Palavras-chave: Recursos Tecnológicos; Edublog; Educação em Ciências; Educação Ambiental.

1Universidade do Estado do Pará. E-mail: vitoria.catmartins@outlook.com

2Universidade do Estado do Pará. E-mail: raquelcardos0933@gmail.com

${ }^{3}$ Faculdade de Tecnologia de Indaiatuba-SP. E-mail: aldopontes@hotmail.com

${ }^{4}$ Universidade do Estado do Pará. E-mail: altempontes@hotmail.com 


\section{Introdução}

No Brasil, a utilização de tecnologias da informação e comunicação (TICs) em contexto escolar vem crescendo nos últimos anos (ALMEIDA et al., 2015). Porém, o bom uso do professor no sentido de incorporar essas tecnologias, ainda está condicionada a fatores limitantes como: a falta de infraestrutura nas escolas para receber as mudanças nas práticas educativas que as Políticas Públicas em educação exigem, resistência por parte da classe docente no uso de tecnologias em algumas situações didáticas, falta de vivências com os recursos tecnológicos no período de formação docente e a escassa formação continuada em áreas de tecnologias educacionais (CONTRERAS; ARANCIBIA, 2013; GARRIDO, CONTRERAS; MIRANDA, 2013).

Conforme Prestridge (2014), o docente se vê obrigado a sofrer atualizações e se reconfigurar bruscamente ao novo, pois a geração $Y$ está cercada por tecnologias mais motivadoras que as aulas tradicionais. Lopes, Monteiro e Mill (2014) ratificam que as metodologias tradicionais utilizadas na escola tratam o conhecimento muitas vezes fora do contexto, assim as trocas de experiências e o aprendizado são menores, limitados, pouco efetivos.

$O$ pensamento de construir e articular conhecimentos junto com os alunos não pode só despertar o interesse de 'aprender sobre', mas também o poder de 'aprender a ser', atuando e transitando em diferentes áreas e campos, já que esse modo de aprendizagem é, por primazia, a forma como muitos jovens fora da escola desenvolvem uma série de competências ligadas aos letramentos digitais (ROMANCINI, 2014).

Para Marques e Abegg (2012), a utilização das TICs no processo educacional deve fomentar sobre as formas de fazer e pensar, objetivando causar admiração e prazer pelo conteúdo estudado, além de possibilitar um aprendizado interligado com o compartilhamento de ideias e ações que ajudam o professor a superar limites entre os conhecimentos disciplinares e conceituais.

De acordo com Miranda (2012), Souza (2015) e Santos et al. (2017), os blogs, como frutos dessa revolução digital, servem para organizar um novo tempo/espaço de ensino e interação, possibilitando o acesso às informações em qualquer período e até mesmo disponibilizar muitas outras online. Porém, esses têm uso limitado porque muitas escolas não têm acesso à internet, computadores, enquanto que as que têm alcance a essa tecnologia muitas vezes "engavetam" essas ferramentas devido não haver educadores com formação suficiente adequada para usar corretamente esses recursos com potencial educativo (PINYA; TUR; ROSSELLÓ, 2016; SANTIAGO; LIMA, 2013).

Para os blogs serem utilizados como ferramenta e troca de experiências na educação, é preciso que o professor além de formação tenha auxílio por parte da comunidade escolar, já que a infraestrutura precisa acompanhar o ritmo da concorrência digital, preparo e formação para ser o mediador e não só o portador do conhecimento (PROSZEK; FERREIRA, 2009; CARVALHO, 
2013). Então, um passo adiante para que o quadro e o pincel não sejam os únicos mecanismos utilizados como recurso educacional é que o professor assuma a responsabilidade de ser o 'aprendiz', transformando-se em uma ponte entre os temas contidos no blog e o aluno (SANTIAGO; LIMA, 2013).

Considera-se importante incorporar os recursos tecnológicos nas propostas educativas porque, segundo Miranda (2012), o professor ao selecionar os conteúdos utilizando links, sínteses, vídeos ou propostas de jogos, faz com que os alunos comentem, consultem e selecionem outros temas para serem pesquisados, tornando esta ferramenta um repositório dinâmico e vivenciado por todos. Nessa perspectiva, com a criação e uso do blog, as publicações podem ser selecionadas e publicadas em tempo real; desenvolvese a escrita de textos que podem ser lidos e comentados, promovendo dinamicidade e interatividade para além das "portas" da sala de aula; a linguagem é adequada ao perfil da juventude moderna, sendo possível buscar uma infinidade de assuntos e organizá-los de forma cronológica (LIMA, ANDRIOLA; TAVARES, 2015).

Araújo (2009) diz que é salutar o professor se apropriar do ato de "blogger" para explorar junto com os leitores possibilidades de debater temas atuais por meio da publicação de textos, vídeos, imagens, animações, referências bibliográficas ou hiperlinks. Dessa maneira, o professor precisa estar inovando suas formas de ensino, conforme as alterações contemporâneas que são vivenciadas por seus alunos.

A inserção de computadores ou o uso de mídias sociais no ensino não pode ser vista como a solução para todos os problemas presentes no processo educacional, mas deve ser colocado como instrumento que facilite na disseminação de conteúdos educacionais (COSTA, 2016). Esse autor acredita que a formação docente é o principal aspecto a ser analisado, pois o profissional deve compreender e saber utilizar os diversos benefícios que as tecnologias podem gerar para melhorar suas aulas.

Considerando o uso das tecnologias na formação ambiental, modalidade cada vez mais presente na Educação Básica (CARAMELLO; STRIEDER, 2011; SILVA; CAMPINA, 2011) com os blogs, é possível interligar os temas ambientais de forma atraente, que aproxime professor e aluno, proporcionando reflexão, ligação do professor com o mundo, trocando experiências com os colegas e dando visibilidade ao trabalho (MIRANDA, 2012).

Com o uso da tecnologia, o mais importante é gerenciar o espaço virtual com seriedade, integrando-o de forma inovadora, equilibrada e aberta com o ensino, para ampliar os benefícios do ambiente dos blogs no contexto educacional (SALLA; SILVA; CAIXETA, 2015). Partindo desses pressupostos, o objetivo do presente artigo é apresentar os resultados de uma pesquisa que identificou as principais temáticas ambientais de interesse para alunos da educação básica e do ensino superior e, com isso, criou, utilizou e avaliou as potencialidades de um blog como ferramenta educacional na temática ambiental e no ensino de Ciências. 


\section{Metodologia}

A metodologia baseou-se em uma abordagem quali-quantitativa, de natureza aplicada (GIL, 2009). Quanto aos objetivos, a pesquisa foi exploratória pois trata-se de um estudo inicial sobre a ferramenta tecnológica selecionada. No que se refere aos procedimentos técnicos, a pesquisa foi bibliográfica com atividade de campo. A pesquisa de campo foi desenvolvida para fazer um levantamento dos temas ambientais de maior interesse para os alunos da educação básica e superior para inserção em um blog.

A população consistiu de estudantes da educação básica de escolas públicas e privadas do município de Belém, no Estado do Pará. Além disso, foram pesquisados alunos de diversos cursos de graduação de Universidades públicas e privadas no campus de Belém.

Para o levantamento de temas ambientais, que foram posteriormente inseridos no blog, a amostra consistiu de 139 estudantes de instituições públicas e privadas do ensino fundamental, médio e graduandos do ensino superior do município de Belém, conforme indica a Tabela 1.

Tabela 1: Amostra dos estudantes que responderam o questionário da pesquisa.

\begin{tabular}{|c|c|c|c|}
\hline \multicolumn{4}{|c|}{ Amostra dos estudantes } \\
\hline $\begin{array}{l}\text { Número de } \\
\text { estudantes }\end{array}$ & Nível educacional & Cidade & Sigla \\
\hline 3 & 9을ie do Ensino Fundamental & Belém-PA & EF-9BE \\
\hline 4 & 1 Série do Ensino Médio & Belém-PA & EM-1BE \\
\hline 6 & $2^{\circ}$ Série do Ensino Médio & Belém-PA & EM-2BE \\
\hline 66 & $3^{\circ}$ Série do Ensino Médio & Belém-PA & EM-3BE \\
\hline 60 & Ensino Superior & Belém-PA & ES-BE \\
\hline
\end{tabular}

Fonte: Elaborado pelos próprios autores.

Para atingir os objetivos propostos, dividiu-se o procedimento em três partes: i. levantamento dos temas ambientais; ii. criação de blog educativo (edublog); iii. oficina de utilização do edublog.

\section{Levantamento dos temas ambientais}

Para o levantamento dos temas ambientais, foi elaborado um questionário para ser respondido online na plataforma Google Docs. O questionário foi constituído de seis perguntas - quatro abertas e duas fechadas. As questões abertas identificavam a idade, o sexo, a série e a instituição de ensino do respondente. Nas perguntas fechadas, foram investigados os temas ambientais de maior interesse dos respondentes e quais temas gostariam de estudar ou se informar. A coleta de dados relativa aos temas ambientais foi realizada nos meses de janeiro e fevereiro de 2017.

No momento do preenchimento do questionário, o participante da pesquisa tinha acesso ao Termo de Consentimento Livre e Esclarecido (TCLE). 
Nesse sentido, só foram contabilizados nesta pesquisa os respondentes que estavam de acordo com o TCLE.

\section{Criação de edublog}

A partir das respostas contidas nos questionários, criou-se no mês de fevereiro de 2017 o edublog "Meio Ambiente e o Ensino de Ciências"' que disponibilizou textos, vídeos, animações e GIFs referente às 22 temáticas mais citadas pelos estudantes. Cruzadinhas e quizzes também foram desenvolvidos e inseridos no blog por meio do programa Hotpotatoes versão 6.3.5.

A mídia social, facebook ${ }^{5}$, criada no mês de fevereiro de 2017 foi utilizada como recurso para a divulgação dos conteúdos presentes no edublog. Após a criação e implementação do edublog, foi possível identificar, entre os 22 temas publicados, quais tiveram maior acesso, sendo isto possível por meio da contagem das visualizações dos conteúdos postados, além de outras estatísticas apresentadas pelo edublog.

\section{Oficina de criação e utilização do edublog}

Para auxiliar na formação de professores sobre as TICs no ensino de Ciências, foi realizada uma oficina sobre como criar blogs, utilizando e divulgando as temáticas ambientais do edublog "Meio ambiente e o Ensino de Ciências". Esta oficina foi realizada no Centro de Ciências e Planetário do Pará (CCPP), especificamente no Laboratório Interdisciplinar de Formação de Educadores (LIFE), em uma atividade de caráter interdisciplinar, com 17 graduandos do Curso de Licenciatura em Ciências Naturais da Universidade do Estado do Pará (UEPA), tendo como temática principal "Blog: Uma importante ferramenta tecnológica". Ao final da oficina, os graduandos responderam a um questionário cujos relatos subsidiaram na avaliação e aplicação da metodologia apresentada.

A análise de dados foi realizada com base em estatística descritiva, que subsidiou a elaboração de Figuras e Tabelas. Além disso, empregou-se estatística não paramétrica - o teste $G$ - para identificar a presença de diferença significativa entre as médias dos parâmetros estudados. O nível de confiança adotado nesta pesquisa foi de $95 \%$, o que corresponde a um nível de significância $p \leq 0,05$.

\section{Resultados e Discussão}

A Tabela 2 apresenta as características da amostra de sujeitos que foi objeto de estudo desta pesquisa. $O p$-valor foi calculado usando estatística não paramétrica - 0 teste $G$.

${ }^{4}$ Disponível em: http://meioambienteoensinodeciencias.blogspot.com.br/

5 Disponível em: https://web.facebook.com/CienciaEambiente/

Revbea, São Paulo, V. 13, № 4: 190-206, 2018. 
Tabela 2: Características da amostra de estudantes que responderam o questionário da pesquisa.

\begin{tabular}{|c|c|c|c|c|c|c|}
\hline $\begin{array}{c}\text { Características } \\
\text { socioeconômicas }\end{array}$ & EF-9BE & $E M-1 A B$ & EM-2BE & EM-3BE & ES-BE & $p$-valor \\
\hline \multicolumn{7}{|l|}{ Sexo $^{a}$} \\
\hline Feminino & 0 & 4 & 3 & 18 & 40 & \multirow{2}{*}{$<0,0001$} \\
\hline Masculino & 3 & 0 & 3 & 48 & 20 & \\
\hline \multicolumn{7}{|l|}{ Faixa etária (anos) $^{a}$} \\
\hline Menor de 16 & 1 & 4 & 2 & 19 & 0 & \multirow{4}{*}{$<0,0001$} \\
\hline 17 a 20 & 0 & 0 & 4 & 32 & 29 & \\
\hline 21 a 24 & 0 & 0 & 0 & 7 & 20 & \\
\hline Acima de 25 & 2 & 0 & 0 & 8 & 11 & \\
\hline \multicolumn{7}{|l|}{ Semestre $a, b$} \\
\hline $1^{\circ}$ até $2^{\circ}$ semestre & 0 & 0 & 0 & 0 & 31 & \multirow{4}{*}{$<0,0001$} \\
\hline $3^{\circ}$ até $4^{\circ}$ semestre & 0 & 0 & 0 & 0 & 8 & \\
\hline $5^{\circ}$ até $6 \stackrel{\circ}{\text { semestre }}$ & 0 & 0 & 10 & 15 & 12 & \\
\hline Acima do $7^{\circ}$ semestre & 2 & 0 & 5 & 6 & 8 & \\
\hline
\end{tabular}

${ }^{a}$ Teste G. ${ }^{b}$ Apenas para o ensino superior

Fonte: Elaborado pelos próprios autores.

De acordo com a Tabela 2, os resultados indicam que houve diferença significativa ( $p$-valor $<0,0001)$ em todas as características analisadas - sexo, faixa etária e semestre - em termos da escolaridade da amostra. Esse $p$-valor é muito pequeno, indicando uma forte relação entre essas varáveis. Essa diferença fica evidente porque a maioria dos estudantes da amostra é do sexo masculino, está concentrada na faixa etária de 17 a 20 anos e cursa o $5^{\circ}$ ou 6 ㅇ semestre da Educação Superior.

A partir da Tabela 2, verifica-se que a maioria dos respondentes da amostra cursa a $3^{\text {a }}$ Série do Ensino Médio ou é estudante de cursos de Ensino Superior. Diante das respostas dos estudantes do ensino básico, foram selecionados os 11 temas ambientais mais indicados por eles. Após inseri-los no Blog "Meio Ambiente e o Ensino de Ciências", verificou-se o número de visualizações, conforme descrito na Figura 1 


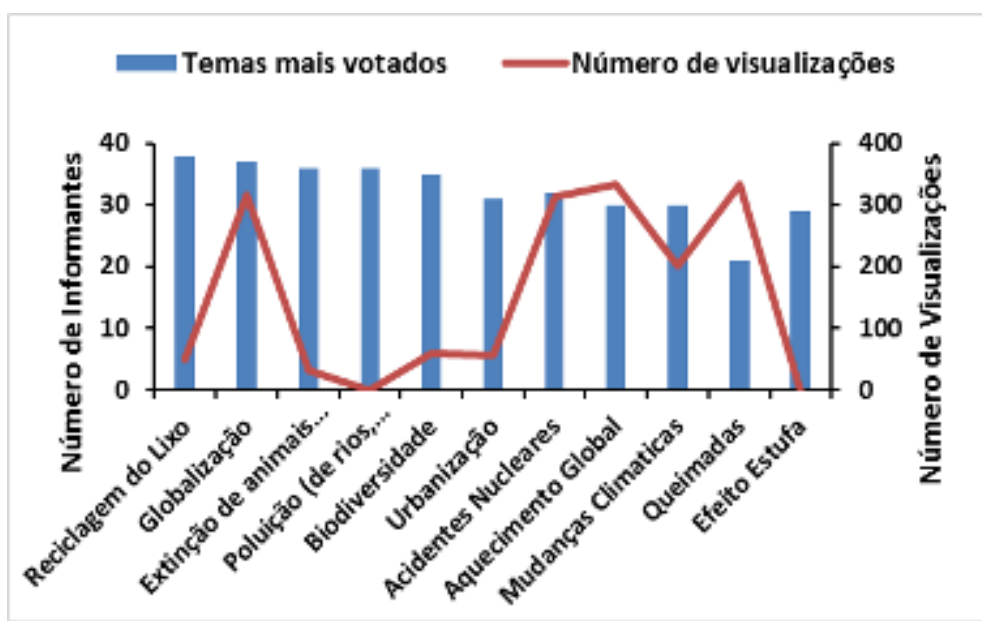

Figura 1: Temas ambientais escolhidos por estudantes da Educação Básica em termos do número de visualizações. Fonte: Elaborado pelos próprios autores.

A temática "Reciclagem do Lixo" foi o tema de maior interesse da amostra da Educação Básica desta pesquisa. Esse tema está largamente presente em livros didáticos do ensino médio, como o Química Cidadã ${ }^{6}$ (2013) e o Meio ambiente Cidadania Tecnologia - Química (2013) ${ }^{7}$. Nos capítulos destes livros são abordados principalmente os descartes e contaminantes gerados por diversos materiais, como os plásticos, sendo a reciclagem do lixo uma das formas que mais aparece para diminuir essas ações.

A influência dos livros didáticos é perceptível mesmo em um período quando a tecnologia, cada vez mais, vem ocupando espaço nas salas de aula. Isso ocorre porque, muitas instituições de ensino não têm laboratório de informática com acesso à internet. Outro obstáculo que vem sendo superado é quanto à formação de professores que, em sua maioria, não possui uma boa formação para a utilização das TICs, logo temem usar essas ferramentas digitais nas aulas (SOUSA; MIOTA; CARVALHO, 2011).

Autores como Souza e Silveira (2010) alertam para a importância de os professores de Ciências se voltarem para as práticas contemporâneas de Educação Ambiental, fundamentando-se em informações atualizadas, comunicando-se melhor e tendo seus alunos ativos na construção do conhecimento. As abordagens das Ciências Ambientais contrapõem com os paradigmas educacionais presentes no ensino, já que os blogs, ao propiciarem a articulação de saberes, facilitam a interdisciplinaridade, reduzindo fatores ainda presentes no conhecimento científico como a linearidade, a disciplinaridade e a fragmentação (GERHARD; FILHO, 2012).

Durante a análise e verificação dos assuntos mais acessados no blog, constatou-se que houve no total mais de 4.000 visualizações, sendo que a temática ambiental mais visitada foi sobre aquecimento global e suas ocorrências com o total de mais de 333 visualizações; o tema efeitos das queimadas no ambiente teve mais de 328 visualizações; o terceiro tema de

6 SANTOS, W.; MOL, G. Química cidadã. Vol 1,2,3, 2ª ed. Ed AJS, São Paulo, 2013.

7 REIS, M. Química: meio ambiente, cidadania e tecnologia. Vol 1,2,3, 1ª ed. Ed Ática, São Paulo, 2013.

Revbea, São Paulo, V. 13, № 4: 190-206, 2018. 
maior interesse foi a globalização, com mais de 314 visualizações, conforme a Figura 1.

Nas respostas dos estudantes do ensino superior, notou-se que os 11 temas ambientais mais votados foram distintos em relação aos temas apontados pelos estudantes do nível básico. Após inserir os temas no edublog "Meio Ambiente e o Ensino de Ciências", verificou-se também o número de visualizações de cada tema, conforme indica a Figura 2.

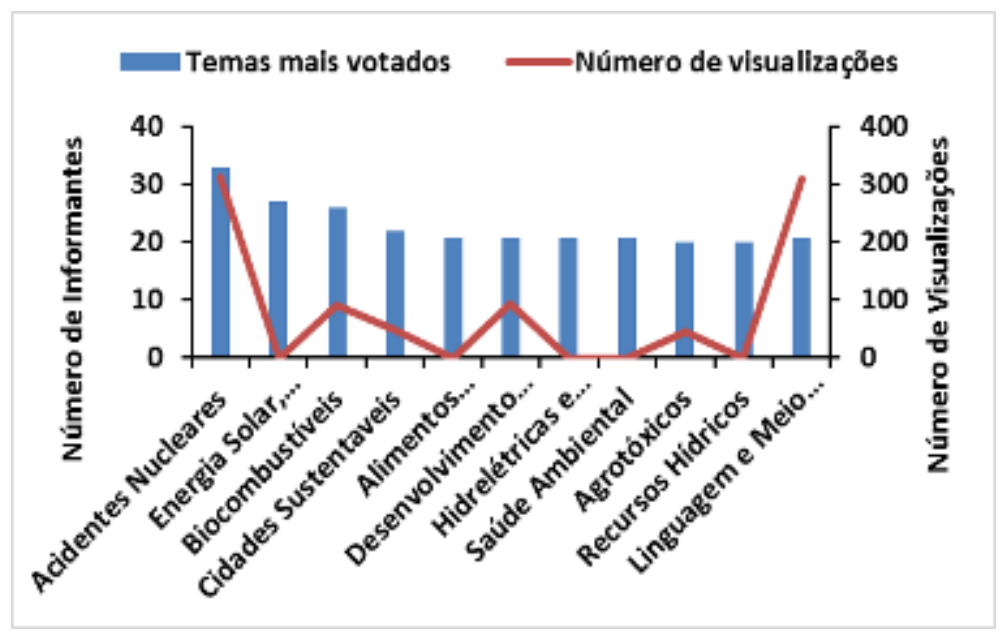

Figura 2: Temas ambientais escolhidos por estudantes do Ensino Superior em termos do número de visualizações. Fonte: Elaborado pelos próprios autores.

Comparando-se as temáticas apontadas como de interesse pelos ensinos básico e superior, pode-se constatar que houve apenas um tema em comum, "Acidentes Nucleares". Esse tema apresenta grande relevância porque a energia nuclear tem várias aplicações como na indústria, na medicina, na agricultura, etc.

Guimarães, Wiggers e Tocantins (2015) afirmam que as mídias e as tecnologias vêm provocando alterações consideráveis na cultura dos jovens e apontam um novo campo de estudo educacional conhecido como mídiaeducação. Quanto as temáticas Energia Solar, Eólica e das Marés; Biocombustíveis, a segunda e terceira mais votadas, percebe-se que há uma semelhança entre elas, pois estão relacionadas com formas de geração de energia, indicando que os entrevistados possuem curiosidade e também um interesse pelos sistemas energéticos.

Os Parâmetros Curriculares Nacionais/Ciências Naturais - PCN (1999) citam o tema "alimentos" como relevante porque, ao categorizar os recursos naturais entre renováveis e não renováveis, pode-se abordar e discutir a instabilidade desses conceitos. Dessa maneira, a excessiva interferência nos ciclos naturais leva à multiplicação da escassez ou destruição de recursos como a água e o solo fértil, estes que são renovados pelos ciclos da natureza. 
Buscando conectar possibilidades no blog criado, e relacioná-las ao contexto escolar, foi inserido um poema intitulado 'Linguagem e o meio ambiente', que obteve mais de 310 visualizações. A leitura dos diferentes gêneros textuais problematizando com os conteúdos apresentados no blog quando realizada com propriedade, garante o envolvimento do sujeito com as práticas discursivas, alterando "seu estado ou condição em aspectos sociais, psíquicos, culturais, políticos, cognitivos, linguísticos e até mesmo econômicos" (SOARES, 1998, p.18)

$\mathrm{O}$ acesso às temáticas mais acessadas ou menos acessadas pode estar relacionado com o acréscimo de vídeos, GIF, hiperlinks, imagens e até mesmo à elaboração de textos mais profundos e baseados em artigos científicos, sendo que nem todas as temáticas possuíam esses recursos ou estavam em menor quantidade, o que pode ter influenciado na quantidade de visualizações. Para Dutra et al. (2006), essas ferramentas podem auxiliar no aprofundamento dos temas propostos em sala de aula, explorando estratégias pedagógicas e linguagens diferentes, despertando no estudante a curiosidade e o interesse pelas ciências e fazendo com que o processo de construção do conhecimento seja mais eficaz. No geral, as temáticas ambientais escolhidas estão sendo bastante pesquisadas pelo público. No entanto, o tema 'Acidente Nucleares' com mais de 313 visualizações, possuiu o maior número de comentários, sete.

Conforme Nunes e Chaves (2016) e Neto et al. (2013), o estudante passa a dialogar com seus leitores e o professor em espaços destinados aos comentários, em que o leitor pode opinar, solicitar novos conteúdos e interagir na web com o autor, criando, desse modo, um espaço virtual que proporciona uma construção coletiva e colaborativa muito abrangente e interdisciplinar. Santos et al. (2014) dizem que os blogs são encarados pelos jovens como uma atividade divertida e lúdica de estudar, permitindo que no ato da leitura haja a articulação com outros tipos de recursos tais como livros, revistas e jornais. Maia, Mendonça e Struchiner (2007), ao realizarem uma pesquisa do uso dos blogs na área de ensino de Ciências, concluíram que são poucos os professores de Ciências que acreditam e buscam como estratégia pedagógica interagir com o uso dos blogs em sua prática educativa, por isso tornam-se relevantes estudos sobre a criação dessa ferramenta.

Ao realizarem um trabalho sobre blogs no ensino de Química, Barro e Queiroz (2010) constataram que eram utilizados como um meio de consulta, avaliação e publicação de temas, muitas vezes, não abordados em livros didáticos, sendo suporte e recurso didático para os alunos do ensino médio e superior de química. Pinya, Tur e Rosselló (2016) apresentam o blog como ferramenta de aprendizagem que auxilia no processo reflexivo e no ensinoaprendizagem por meio dos feedbacks de caráter formativo e as redes sociais que fornecem o desenvolvimento da competência digital.

O edublog foi elaborado a partir da plataforma Blogger, do Google, e está de acordo com os critérios de Rodrigues (2008), que diz que é necessário haver a gratuidade da ferramenta, o fácil manuseio e a estrutura intuitiva e agradável. A plataforma apresenta o título "Meio ambiente e o Ensino de Revbea, São Paulo, V. 13, № 4: 190-206, 2018. 
Ciências", possui design ambiental, permitindo a publicação de textos, comentários, inserção de hiperlinks, jogos, GIF, vídeos e podcast.

Gomes e Lopes (2007) afirmam que os blogs podem ser utilizados em diferentes níveis de escolaridade, com múltiplos objetivos educacionais e, em diversas disciplinas. Assim, são instrumentos que podem relacionar o ensino de Ciências e a Educação Ambiental com outras características, repensando os critérios de escolha dos conteúdos ensinados, buscando estabelecer novas relações educacionais e, assim, auxiliar na efervescência da educação e a comunicação (VALENTE, 2014), conforme indica a Figura 3.

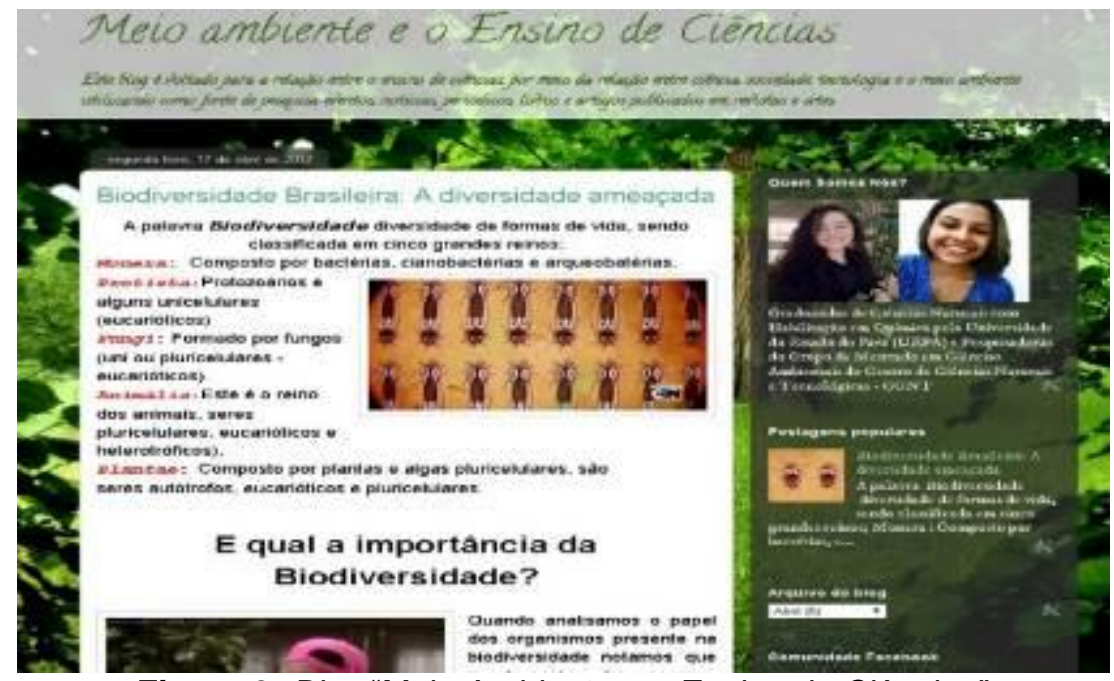

Figura 3: Blog "Meio Ambiente e o Ensino de Ciências"

Fonte: Elaborado pelos próprios autores

Para aproximar os leitores e os contextos abordados, utilizou-se uma linguagem adaptada para o ambiente digital. Lima e Pinheiro (2015) expõem que essas ferramentas apresentam sua própria linguagem caracterizadas pelos discursos que estão envolvidos nesses sistemas, sendo adaptadas de acordo com o contexto e o público.

Devido à ferramenta de tradução do Google está disponível no "Meio Ambiente e o Ensino de Ciências", estatisticamente constatou-se que os países que mais visualizaram os assuntos contidos no blog foram os Estados Unidos e o Brasil, respectivamente, primeiro e segundo lugar. Assim, para promover um aprendizado dinâmico e didático, foi inserido no blog jogos por meio do programa Hotpotatoes versão 6.3.5, como a cruzadinha "Desafio Ecológico" com mais de 43 acessos e o quiz "Top 10", que desafia perguntas sobre os temas urbanização, reciclagem do lixo e extinção, com mais de 40 acessos, fora outros recursos inseridos no blog.

Para responder as perguntas da cruzadinha científica, o participante deveria conhecer as temáticas ambientais abordadas no blog, ficando atento ao tempo estipulado pelo cronômetro de cada jogo. Nessa perspectiva, a 
inserção dos jogos na plataforma virtual provocou o surgimento de comentários positivos por parte dos leitores, evidenciando que os jogos utilizados para o ensino de Ciências são ferramentas que podem facilitar o entendimento de assuntos científicos, buscando entender todo o conjunto que faz parte do conceito.

Para Paula e Valente (2016), o uso de jogos na educação deve estar associado a construção do conhecimento científico, que o aluno seja o centro da ação, exigindo que decisões sejam tomadas frente ao contexto problemático. Os autores ainda ressaltam que os jogos precisam apresentar desafios para assim motivar o estudante a compreender diversas temáticas e com isso, possivelmente associá-las à sua realidade.

Para ajudar na divulgação das publicações, eventos e outros assuntos presentes no blog, foram criadas páginas adequadas para a modalidade de ensino, na mídia social facebook, obtendo mais de 100 curtidas e utilizando-se de imagens, notícias, hiperlinks e GIF. Dessa forma, foi possível verificar, pelas estatísticas do blog, que a origem do tráfego que mais acessa o "Meio Ambiente e o Ensino de Ciências" advém das mídias sociais criadas.

Nesse aspecto, Minhoto e Meirinhos (2011) e Juliani et al. (2012) afirmam que a produção de reflexão e compartilhamento de ideias nas mídias digitais de forma coletiva $e$ aos seguidores proporcionam pesquisas relacionadas aos assuntos de seu interesse. Dessa maneira, ao final da oficina (Figura 4), os graduandos relataram pontos positivos, como:

Aluno B - "Apresentou jogos didáticos que incentivam novos meios de aprendizagem para a escola".

Aluno C - "A divulgação desta ferramenta chamou atenção, pois nunca havia pensado em utilizar este meio para propagar ciência".

Os pontos negativos restringiram-se à falta de tempo para explorar mais recursos do blog, a ausência de mais jogos no blog "Meio Ambiente e o Ensino de Ciências" e a resistência de alguns graduandos em utilizar esse recurso nas escolas, devido as estruturas deficientes de algumas instituições de ensino.

Os graduandos foram questionados se os recursos tecnológicos podem contribuir para o ensino de Ciências. Em resposta, obtivemos os seguintes relatos:

Aluno E - "Sim. Os aparatos tecnológicos podem apresentar exemplos para a ilustração, esclarecendo alguns conceitos abstratos".

Aluno F - "Sim. É uma forma mais dinâmica para aprender as matérias de Ciências". 
Quando foram questionados se o blog "Meio Ambiente e o Ensino de Ciências" pode ser usado como ferramenta de apoio para o ensino de Ciências, obtivemos os seguintes relatos:

Aluno $\mathbf{H}$ - "Sim, pois é uma ferramenta tecnológica didática e que tem os jogos como método de avaliação".

Aluno I - "Sim, com certeza. É um espaço em que o aluno pode buscar até após a aula".

Ao serem questionados se o uso do blog "Meio ambiente e o Ensino de Ciências" os motivou para o estudo de Ciências e a criação de outros tipos de blogs, o relato do Aluno $\mathbf{J}$ representa o posicionamento de $100 \%$ dos estudantes, "Sim, a oficina motivou a criar blogs, inclusive o meu, que será das ciências exatas e físicas".

Quando questionados se eles acham importante criar e usar blogs como ferramentas para auxiliar o professor no ensino de Ciências, obtivemos os seguintes relatos:

Aluno $L$ - "Sim, pois como vivemos em uma época onde a informática está em alta, é válido relacionar o ensino a essas novas tecnologias".

Aluno M - "Sim, dependendo da forma de utilização, torna uma aula mais dinâmica e didática para auxiliar o aluno, porém não substitui o professor".

Sobre esse conjunto de respostas, pode-se observar duas vantagens do uso dessas ferramentas que foram expressas nos relatos dos graduandos e também defendidas por Silva e Machado (2009). As tecnologias, ao favorecerem as outras possibilidades de aprender, proporcionam estímulos, colaborando com os futuros docentes na criação e dinamização de conteúdos pedagógicos. Contudo, é preciso ter domínio sobre as ferramentas tecnológicas que serão utilizadas por parte dos professores, para que se habituem com essas, assim como ocorreu com os livros e as lousas na era industrial.

É preciso desmistificar o fato de os blogs terem como objetivo servirem apenas como repositórios de informação e entretenimento. Barro e Queiroz (2010) dizem que o desafio para aplicação dos blogs em outras áreas, principalmente no ensino de Ciências, é propor que esses sejam objetos de uso, tendo em vista finalidades maiores dentre as quais a promoção da aprendizagem colaborativa, cooperativa e reflexiva no ensino, explorando na formação de professores a criação de jogos, mídias sociais e outros estilos de blog, promovendo uma discussão reflexiva desses, assim como algum conceito chave importante nas aulas. 


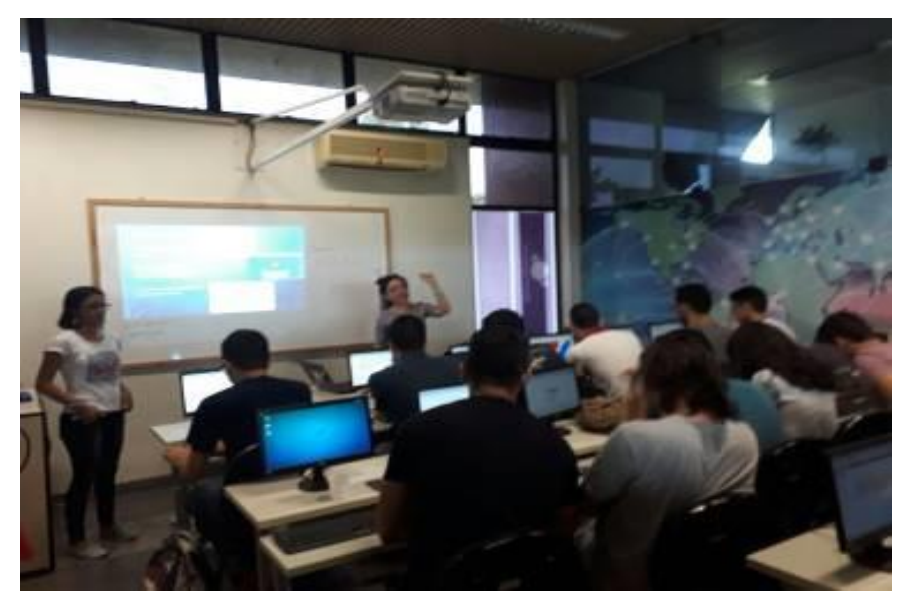

Figura 4: Oficina "Blog: Uma importante ferramenta tecnológica".

Fonte: Elaborado pelos próprios autores

\section{Conclusão}

As tecnologias ainda são vistas com receio por alguns docentes, pois em sua formação não obtiveram um contato mais efetivo e contínuo com esses recursos. Esse fator torna-se um obstáculo em relação à construção do conhecimento, visto que pode condicionar a um baixo potencial educativo e consequentemente um rendimento escolar inferior.

Os blogs, com ferramentas resultantes de um processo evolucionista e tecnológico, proporcionam o desenvolvimento do conhecimento de uma forma lúdica e prazerosa, de maneira que 0 aluno tem a oportunidade de compreender alterações existentes no mundo através das temáticas ambientais inseridas no ensino de Ciências e na Educação Ambiental.

O professor é o principal mediador na utilização dessa outra metodologia, tendo o papel de professor-aprendiz, aquele que associa o ensino com as alterações contemporâneas. O blog "Meio Ambiente e o Ensino de Ciências" é um exemplo essencial para a apresentação dos edublogs como instrumentos que auxiliam na aprendizagem sobre temas ambientais. Vale ressaltar que os temas utilizados no edublog alcançaram dimensões internacionais, e alguns assuntos foram destaques, como a reciclagem do lixo e os acidentes nucleares que são conteúdos abordados constantemente nos meios de comunicação e informação.

A divulgação da plataforma na página no facebook foi essencial para o crescimento de acessos no edublog, a qual obteve mais de 100 curtidas e assim, por meio do compartilhamento dos temas, identificou-se os interesses dos seguidores em relação a cada contexto abordado. Partindo disso, na aplicação do edublog com os graduandos, pôde-se constatar que as novas ferramentas tecnológicas possibilitam um pensar mais didático e colaborativo, apresentando aos futuros docentes as diversas oportunidades que são geradas com esses recursos.

As escolas que atualmente recebem equipamentos como computadores com internet e projetores multimídia devem atentar para a formação de seus professores, pois como mediadores dos contextos estudados, são Revbea, São Paulo, V. 13, № 4: 190-206, 2018. 
responsáveis pela disseminação do conhecimento científico para com seus alunos. A formação continuada dos educadores torna-se essencial para 0 desenvolvimento de novas metodologias capazes de aproximar alunos e professores visando avançar de modelos tradicionais, vistos em muitas situações, como barreiras para o ensino e a aprendizagem atualmente, para modelos educativos mais coerentes com as demandas por conhecimento deste tempo.

\section{Referências}

ALMEIDA, J. M. de; CASTELANO, K. L.; SANTO, J. A. do. E.; SOUZA, C. H. M. de; LUQUETTI, E. C. F. Uso de Blog na escola: recurso didático ou objeto de divulgação? InterSciencePlace, v. 1, n. 22, p. 174-193, 2015.

ARAÚJO, M. C. M. U. Potencialidades do uso do blog em educação. 2009. 207f. Dissertação (Mestrado em Educação) - Centro de Ciências Sociais Aplicadas, Universidade Federal do Rio Grande do Norte - UFRN, Natal, 2009. Disponível em: <ftp://ftp.ufrn.br/pub/biblioteca/ext/bdtd/MicheleCMUA.pdf.>. Acesso em: 14 nov. 2017.

BARRO, M. R.; QUEIROZ, S. L. Blogs no ensino de química: análise dos trabalhos apresentados em eventos da área. In: ENCONTRO NACIONAL DE ENSINO DEQUÍMICA (ENEQ), 15, 2010, Brasília. Anais eletrônicos... Brasília: Sociedade Brasileira de Química, 2010. Disponível em:< http://www.xveneq2010.unb.br/resumos/R0831-1.pdf >. Acesso em: 10 out. 2017.

CARAMELLO, G. W.; STRIEDER, R. B. Elementos para inserir questões ambientais em aulas de Física: da prática baseada em temas à complexificação do conhecimento. Pesquisa em Educação Ambiental. v. 6, n.2, p.101-117, 2011.

CARVALHO, P. M. S. de. O uso de Blogs e aulas experimentais como práticas educativas no ensino de físico-química para o ensino médio: Um estudo descritivo a partir do conceito de aprendizagem significativa. 2013. $122 f$. Dissertação (mestrado) - Centro de Ciências, Universidade Federal do Ceará - UFC, Fortaleza, 2013. Disponível em: <http://www.repositorio.ufc.br/handle/riufc/5941>. Acesso em: 14 nov. 2017.

CONTRERAS, P.; ARANCIBIA, M. Aprendizagem e TIC: ensino inovações para transformar contextos educativos. Estudos Pedagógicos (Valdivia), v.39, Edição Especial I, p. 5-6, 2013..

COSTA, M. L. C da. O Edublog como recurso didático no ensino da matemática escolar. Revista EPBEM. v.1, n.2,s/p, 2016.

DUTRA, Í. M.; PICCININI, C. A.; BECKER, J. L.; JOHANN, S. P.; FAGUNDES, L. da C. Blog, wiki e mapas conceituais digitais no desenvolvimento de projetos de aprendizagem com alunos do ensino fundamental. RENOTE - Revista Novas Tecnologias na Educação, v. 4, n. 2, on- line,. 2006. 
GARRIDO, J.; CONTRERAS, D.; MIRANDA, C. Análise da oferta educativa para os futuros professores para utilizar as TIC. Estudos Educacionais (Valdivia), v. 39, Edição Especial I, p. 59-74, 2013.

GERHARD, A. C.; ROCHA FILHO, J. B. A Fragmentação dos saberes na educação científica escolar na percepção de professores de uma escola de ensino médio. Investigações em Ensino de Ciências, v.17, n.1, p. 125-145, 2012

GIL, A. C. Como elaborar projetos de pesquisa. 4 ed. São Paulo: Atlas, 2009.

GOMES, M. J.; LOPES, A. M. Blogues Escolares: quando, como e porquê? In: Actas da Conferência Weblogs na Educação - 3 testemunhos, 3 experiências. Setúbal: Centro de Competências CRIE da ESE de Setúbal. p. 117 - 133. 2007. Disponível em: <https://repositorium.sdum.uminho.pt/ bitstream/1822/6487/1/gomes2007.pdf > Acesso em: 01 nov 2017.

GUIMARÃES, J. S.; WIGGERS, I. D.; TOCANTINS, G. M. O. Mídia-Educação e Escola: Meios Digitais e Cultura Popular. Cadernos de Pesquisa, v.45, n.158, p.996-1000, 2015

JULIANI, D. P.; JULIANI, J. P.; SOUZA, J. A. de; BETTIO, R. W. de. Utilização das redes sociais na educação: Guia para uso do facebook em uma instituição de ensino superior. CINTED-Centro de interdisciplinaridade de novas tecnologias, v. 10, n.3, 2012.

LIMA, A. S.; ANDRIOLA, W. B.; TAVARES, W. A. Melhorando o processo de ensino e aprendizagem na área da computação por meio da utilização de edublogs. Revista Ibero-Americana de Estudos em Educação, v.10, n. 3, jul, set. 2015.

LIMA, A. M. P.; PINHEIRO, R. C. Os multiletramentos nas aulas de língua portuguesa no Ensino Médio. Linguagem \& Ensino, v.18, n.12, p.327-354, 2015.

LOPES, A.H.R.G.P.; MONTEIRO, M.L.; MILL, D.R.S. Tecnologias Digitais no contexto escolar: Um estudo bibliométrico sobre seus usos, suas potencialidades e fragilidade. Revista Eletrônica de Educação, v. 08, n.02, p.30 - 43, 2014.

MARQUES, E. G.; ABEGG, I. Blog como ferramenta pedagógica na produção colaborativa em Educação Ambiental. In: Monografias Ambientais, v.10, n. 10, p. 2115 - 2127, out - dez, 2012.

MAIA, F.; MENDONÇA, L.; STRUCHINER, M. Blogs e ensino de ciências: um estudo exploratório. In: ENPEC, 6, 2007, Florianópolis. Disponível em: < http://www.fae.ufmg.br/abrapec/\%20viempec/CR2/p1119.pdf > Acesso em: 11 nov 2017.

MINHOTO, P.; MEIRINHOS, M. As redes sociais na promoção da aprendizagem colaborativa: um estudo no ensino secundário. Educação, Formação e Tecnologias, v.4, n.2, p.25-34, 2011.

Revbea, São Paulo, V. 13, № 4: 190-206, 2018. 
MINISTÉRIO DA EDUCAÇÃO. Secretária de Educação Básica Média e Tecnológica. Parâmetros curriculares nacionais de ciências naturais: ensino fundamental. Brasília: MEC, 1999.

MIRANDA, F. H. da. F. Uso de blog em Educação Ambiental: uma possibilidade pedagógica. 2012. 75f. Dissertação (Mestrado Profissional em Ensino de Ciências da Saúde e do Meio Ambiente) - Fundação Oswaldo Aranha, Centro Universitário de Volta Redonda, RJ. 2012. Disponível em: < http://web.unifoa.edu.br/portal ensino/mestrado/mecsma/arquivos/56.pdf $>$ Acesso em: 11 nov 2017.

NETO, S. R. S.; SANTOS, H. R. M.; SOUZA, A. A. de; SANTOS, W. O. dos. Jogos Educacionais como Ferramenta de Auxílio em Sala de Aula. In: Congresso Brasileiro de Informática na Educação (CBIE), 2, Workshop de Informática na Escola (WIE),19, Campinas. Anais eletrônicos. Campina.2013. Disponível em: < http://www.br-ie.org/pub/index.php/wie/article/view/2634 >. Acesso em: 04 nov 2017.

NUNES, P. R.; CHAVES, A. C. L. Ciano Quiz: um jogo digital sobre cianobactérias como instrumento para a Educação Ambiental no ensino médio. Revista Ciência e Ideais, v.7, n.3, set, dez, 2016.

PAULA, B. H. de; VALENTE, J. A. Jogos Digitais e Educação: Uma possibilidade de mudança da abordagem pedagógica no ensino fundamental. Revista Ibero-Americana de Educação, v.70, n.01, p. 09-28, 2016.

PINYA, C.; TUR, G.; ROSSELLO, M. R. Los blogs en la formación docente inicial. Estud. pedagóg., Valdivia, v. 42, n. 1, p. 223-233, 2016. Disponível em: <http://www.scielo.cl/scielo.php?script=sci arttext\&pid=S0718-0705201600 0100014\&lng=es\&nrm=iso $>$. Acesso em: 19 nov 2017.

PRESTRIDGE, S. J. Reflective blogging as part of ICT professional development to support pedagogical change. Australian Journal of Teacher Education, v. 39, n. 2, p. 70-86, 2014.

PROSZEK, R.; FERREIRA, M. Enseñanza de la química en ambientes virtuales: Blogs. Formación universitaria, v. 2, n. 6, p. 21-30, 2009.

REIS, M. Química: meio ambiente, cidadania e tecnologia. $3 \stackrel{\text { a }}{\text { ed. São }}$ Paulo: Ed Ática, 458p, 2013.

RODRIGUES, C. O uso de blogs como estratégia motivadora para o ensino de escrita na escola. 2008. 158f. Dissertação (Mestrado em Linguística Aplicada) - Instituto da Linguagem, Universidade Estadual de Campinas, SP. 2008. Disponível em: http://bdtd.ibict.br/vufind/Record/CAMP 7e03233964195e6e 127ced154ba7b8d4 > Acesso em: 20 nov 2017.

ROMANCINI, R. Os letramentos digitais e a educação: práticas contextualizadas e escola. 2014. Disponível em: < http://www.plataformadoletramento.org.br/em-revista/714/os-letramentosdigitais-e-aeducacao-praticas-contextualizadas-e-escola.html> Acesso em: 20 nov 2017. 
SALLA, H.; SILVA, R. L. J. da; CAIXETA, J. E. Química do dia-a-dia: a medição do conhecimento a partir do blog e outras tecnologias da informação e comunicação. In: Simpósio Internacional em Educação e Comunicação, 6. Aracaju. Anais Eletrônicos. Aracaju. 2015. Disponível em: < http://proceedings.ciaiq.org/index.php/ciaiq2015/article/view/200/196 >. Acesso em: 04 nov 2017>

SANTIAGO, M. F. C.; LIMA, R. W. de. Blog: Uma Ferramenta de Aprendizagem no Ensino Médio Inovador. Anais do Workshop de Informática na Escola, v. 1, n. 1, p. 80, 2013.

SANTOS, J.; ARRUDA, L.; KHAN, V.; AZEVEDO, R. O uso do Blog no Ensino de Ciências. Revista Areté | Revista Amazônica de Ensino de Ciências, [S.I.], v. 7, n. 12, p. 117-127, maio 2017.

SANTOS, W.; MOL, G (Coords). Química cidadã. 3aㅗ ed. São Paulo: Ed AJS (Coleção Química cidadã), 428p, 2013.

SILVA, R. L. F de; CAMPINA, N. N. Concepções de Educação Ambiental na mídia e em práticas escolares: Contribuições de uma tipologia. Pesquisa em Educação Ambiental. v.6, n.1, p.29-46, 2011.

SILVA, L. A. da; MACHADO, L. R. de S. Tecnologias da informação e comunicação a serviço do trabalho colaborativo, inovações socioeducacionais e desenvolvimento local. Revista Renote - Novas Tecnologias na Educação, CINTED-UFRGS, v.7, n.3, 2009.

SOARES, M. Letramento: como definir, como avaliar, como medir. In: SOARES, M. Letramento: um tema em três gêneros. Belo Horizonte: Autêntica, p. 61-125, 1998a.

SOUSA, R. P.; MIOTA, F. M. C. S. C.; CARVALHO, A. B. G. (Orgs). Tecnologias digitais na educação [online]. Campina Grande: EDUEPB, 276 p. 2011. ISBN 978-85-7879-065-3.

SOUZA, M. de C. A. E. Edublogs, uma estratégia pedagógica: Sequência Didática para a Produção Autoral de Alunos (as) do Ensino Médio. Curitiba PR, 2015. 234f. Dissertação - Mestrado em Ensino de Ciências. Universidade Federal do Paraná, 2015. Disponível em: < https://acervodigital.ufpr.br/handle/1884/40496 > Acesso em: 14 nov. 2017.

SOUZA, R. E. de; SILVEIRA, I. F. A. Utilização do Blog Como Recurso Educacional no Processo de Ensino e Aprendizagem de Tópicos do Currículo de Física e Matemática no Ensino Médio. In: EMBRAPEM, 11, 2010. Campo Grande/MS. Disponível em: < http://ebrapem.mat.br/inscricoes/trabalhos/GT06 SOUZA TA2.pdf > Acesso em: 17 nov 2017.

VALENTE, J. A. A Comunicação e a Educação baseada no Uso das Tecnologias Digitais de Informação e Comunicação. Revista UNIFESO Humanas e Sociais, v.01. n.01. p.141-166, 2014. 